\title{
IS ASTHMA A RISK FACTOR FOR COVID-19 IN CHILDREN?
}

\author{
Cristina Calvo ${ }^{1}$, Ana Hernáiz ${ }^{2}$, Lucía Escolano${ }^{1}$, and Maria Luz García-García ${ }^{3}$ \\ ${ }^{1}$ Hospital Universitario La Paz \\ ${ }^{2}$ Universidad Alfonso X el Sabio Facultad de Ciencias de la Salud \\ ${ }^{3}$ Hospital Universitario Severo Ochoa
}

July 2, 2021

\begin{abstract}
The prevalence of asthma in children in Europe is an average of $10.3 \%$. The role of asthma as a risk factor for COVID-19 in children is unknown. Our aim was to study the prevalence of asthma in children with SARS-CoV-2 infection and to compare them in hospitalized children and those with mild ambulatory symptoms. We conducted an observational retrospective study in 99 children (between 3- 17 years of age) with a confirmed SARS-CoV-2 infection between March and December 2020. The existence of a history of asthma was investigated using the validated ISAAC questionnaire and clinical data on COVID19 were compiled. The median age was 10 years $(\mathrm{IQR}=13-5)$, and 60/99 (60.6\%) patients had mild infections controlled as outpatient, while 39/99 (39.4\%) required admission. The prevalence of asthma -affirmative response to question 6 of the ISAAC questionnaire- was $11.1 \%$ (11/99). The prevalence of asthma in children who required admission increased to $17.9 \%$ and to $21.4 \%$ in patients requiring PICU, while in outpatients children was $6.7 \%(\mathrm{p}=0.079)$. We found a significant association between the use of salbutamol during the last year and the need for admission (23.1\% in hospitalized patients vs $3.3 \%$ in outpatients; $\mathrm{OR}=8.7,95 \% \mathrm{CI} 1.7-42.8)$. Likewise, budesonide treatment in the last year $(17.9 \%$ vs $1.7 \%$, OR $=12.9,95 \%$ CI $1.5-109.5)$ was also a risk factor for admission. Therefore, a history of asthma was not a risk factor for SARS-CoV-2 infection in our series, but active asthma could be a risk factor for severity and need for hospitalization for COVID-19 in children
\end{abstract}

\section{Introduction}

Asthma is one of the most prevalent chronic respiratory diseases in the world. The relationship between COVID-19, caused by SARS-CoV-2 virus, and asthma has not been determined in the pediatric population. According to the International Study of Asthma and Allergies in Childhood (ISAAC) ${ }^{1}$, the average prevalence in children in Spain is $10.3 \%$, a rate similar to that of the European Union.

Since the beginning of the COVID-19 pandemic, studies in adults have shown a relative small number of asthmatic cases among hospitalized patients. It has been proposed that medication (inhaled corticosteroids or immunosuppressants) could play a protective role in asthmatic patients ${ }^{2,3}$. Although SARS-CoV-2 infection is a relatively mild disease in children, pediatric infections account for $10-12 \%$ of diagnoses ${ }^{4}$, and a small percentage require hospitalization even in intensive care units, mostly due to pneumonia or multisystem inflammatory syndrome in children (MIS-C). However, asthma attack is rare among SARS-CoV-2 hospitalized children $^{5}$. A history of asthma is currently a debated risk factor for COVID-19, with few published studies ${ }^{6.7}$. The results of Floyd et $\mathrm{al}^{8}$ study -among the few pediatric studies that examined asthma as a risk factor for COVID-19- did not demonstrate a higher frequency of asthma among those patients hospitalized with COVID-19, through a review of medical records.

Our objective was to study the prevalence of asthma in children with SARS-CoV-2 infection and to compare the frequency of asthma in hospitalized children and those with mild ambulatory symptoms.

\section{Patients \& Methods}


This is a retrospective study carried out in children between 3 and 17 years of age, with a confirmed diagnosis of SARS-CoV-2 infection (by antigen test, PCR or serology) from March to December 2020. The children were cared as outpatients in the Severo Ochoa Hospital (Leganés, Madrid) which and as inpatients in the La Paz Hospital (Madrid) which was a referral center for pediatric hospitalization. All patients were contacted by telephone and informed consent was obtained. The study was approved by the ethics committee of both hospitals. Clinical data of the acute infection were collected, as well as those related with family history of asthma or atopy. The ISAAC questionnaire ${ }^{1}$ was carried out to determine the prevalence of asthma. Asthma was defined as affirmative response to the question 6 of the ISAAC questionnaire, "Has your child ever had asthma?", and it was considered as the main variable of the study.

Statistical analysis was performed using the Statistical Package for the Social Sciences (SPSS), Version 21.0. Values were expressed as percentages for discrete variables, and as median and interquartile range (IQR) for continuous variables. The demographic, clinical and evolutionary characteristics were compared by Chi2, Fisher's exact test and Mann-Whitney test as appropriate. A 2-sided value of $\mathrm{P}<0.05$ was considered statistically significant.

\section{Results}

A total of 141 children between 3 and 17 years of age met the inclusion criteria. Of them, 99 patients agreed to participate or could be contacted. Of these, $52(52.5 \%)$ were female. The median age was 10 years (interquartile range, IQR $=13-5)$. Sixty patients $(60.6 \%)$ had mild infections and were controlled as outpatients, while 39/99 (39.4\%) required hospitalization. Likewise, 14 (14.1\%) children required admission to the Pediatric Intensive Care Unit (PICU) during their hospital stay. The most frequently observed clinical diagnosis was mild respiratory infection in 23 children (23.2\%), followed by pneumonia in 18 children $(18.2 \%)$ and febrile syndrome in 17 cases (17.2\%). It is worth highlighting the frequency of MIS-C, which reached $10.1 \%$ of cases. On the other hand, 11 asymptomatic children (11.1\%) were diagnosed in the context of family contacts (Figure 1).

The prevalence of asthma in our study -defined as affirmative response to question 6 of the ISAAC questionnaire- was $11.1 \%$ (11/99). The prevalence of asthma in children who required admission increased to $17.9 \%$ and to $21.4 \%$ in patients requiring PICU. In contrast, the frequency of asthma in outpatients children with milder disease was $6.7 \%$, although the difference did not reach statistical significance $(p=0.079)$. There were also no statistically significant differences in the prevalence of asthma according to the gender, the clinical diagnosis of SARS-CoV-2 infection or the family history of asthma or atopy.

However, we found a significant association between the use of salbutamol during the past year and the need for admission (23.1\% in hospitalized patients vs $3.3 \%$ in outpatients) with an OR $=8.7,95 \%$ CI 1.7-42.8. Likewise, these patients who needed salbutamol in the past year, had a four times higher risk of requiring PICU admission (28.6\% vs $8.2 \%, \mathrm{OR}=4.5,95 \%$ CI 1.1-17.9). A statistical association was also found between admission for SARS-CoV2 and budesonide treatment in the last year $(17.9 \%$ vs $1.7 \%, \mathrm{OR}=12.9$, $95 \%$ CI $1.5-109.5)$ or budesonide treatment at any time $(30.8 \%$ vs $13.3 \%$, OR $=2.9,95 \%$ CI $1-7.9)$ (Table 1).

\section{Discussion}

The role of asthma as a risk factor for COVID-19 in children is undetermined, and some authors highlight the need for more data ${ }^{7}$. From the results of our series, we found that $11.1 \%$ of SARS-CoV-2 infected children suffer from asthma. This is consistent with the global prevalence of asthma collected by the ISAAC study ${ }^{1}$ from Europe and Spain, which is around $10.3 \%$ in the pediatric population. Based on these observations, we could consider that asthma is not a risk factor for SARS-CoV-2 infection in children.

However, a higher percentage of asthma has been observed in children who required admission or PICU ( $17.6 \%$ and $21.4 \%$ respectively), compared to children with mild infection (6.7\%), although the difference did not reached statistical significance. We do not know if an increase in the sample size could have yielded other results. These data should be taken with caution since they have been obtained evaluating question 6 
of the ISAAC questionnaire that considers the diagnosis of asthma at any time in the child's life. However, when we analysed anti-asthmatic therapy in the previous year, both the use of salbutamol and inhaled corticosteroids were associated with increased risk of hospitalization, up to 8 times higher for salbutamol (4 times in the PICU) and up to 2.9 for budesonide (12 times in the PICU). These data lead us to suggest that active asthma could be a risk factor for more severe disease, higher rates of hospitalization and of PICU admission due to COVID.

Our results are consistent with Floyd et $\mathrm{al}^{8}$ study with more than 1000 children in Philadelphia, in which the authors did not find asthma to be a risk factor for hospitalization. However, the use of anti-asthmatic drugs was more frequent in hospitalized patients. Floyd et al, extracted data from the medical records, an important limitation of their study, while in our case the asthma diagnosis was made using an internationally validated questionnaire and was obtained directly from the parents, thereby reducing the bias of lack of data in the medical records.

Our findings are also similar to a systematic review carried out by Sunjaya et $\mathrm{al}^{9}$ in Australia, including 57 studies (only 4 included children) with more than 300,000 confirmed SARS-CoV-2 infections. The prevalence of asthma in SARS-CoV-2 patients was similar to the prevalence of global asthma (7.46\%). Although the authors found a higher percentage of asthmatics with severe COVID-19 and higher requirement for ICU admission, the difference was not statistically significant.

Recently, a cross-sectional study of 43465 patients under 18 years of age with COVID-19, has been published. More than 25\% of patients had one or more underlying condition. Asthma was found to be a risk factor for hospitalization and clinical severity, although it is not specified whether asthma was a current or previous condition ${ }^{10}$. Finally, $\mathrm{Zu}$ et al ${ }^{11}$, with a different approach, performed a study analysing the genetic predisposition to allergic asthma, employing data from the UK Biobank in 492,768 adult patients and they found an association between non-allergic asthma and severe COVID-19.

Despite our limitations, we conclude that a history of asthma was not a risk factor for SARS-CoV-2 infection in our series, but active asthma could be a risk factor for more severe evolution and need for hospitalization for COVID-19 in children. More studies are needed to clarify the role of asthma in pediatric population with COVID-19.

\section{REFERENCES}

1. Arnedo A, Bellido JB, Pac MR, Artero A, Campos JB, Museros L, Puig-Barbera J, Tosca R, Tornador E. Incidence of asthma and risk factors in a cohort of schoolchildren aged from 6-7 years old to 14-15 years old in Castellon (Spain) following the International Study of Asthma and Allergies in Childhood (ISAAC). Med Clin (Barc). 2007 Jun 30;129(5):165-70. Spanish. doi: 10.1157/13107792. PMID: 17669332.

2. Caminati M, Lombardi C, Micheletto C, Roca E, Bigni B, Furci F, Girelli D, Senna G, Crisafulli E. Asthmatic patients in COVID-19 outbreak: Few cases despite many cases. J Allergy Clin Immunol. 2020 Sep;146(3):541-542. doi: 10.1016/j.jaci.2020.05.049. Epub 2020 Jun 22. PMID: 32620309; PMCID: PMC7306702.

3. Izquierdo JL, Almonacid C, Gonzalez Y, Del Rio-Bermudez C, Ancochea J, Cardenas R, Lumbreras S, Soriano JB. The impact of COVID-19 on patients with asthma. Eur Respir J. 2021 Mar 4;57(3):2003142. doi: 10.1183/13993003.03142-2020. PMID: 33154029; PMCID: PMC7651839.

4. Sisk B, Cull W, Harris JM, Rothenburger A, Olson L. National Trends of Cases of COVID-19 in Children Based on US State Health Department Data. Pediatrics. 2020 Dec;146(6):e2020027425. doi: 10.1542/peds.2020-027425. Epub 2020 Sep 29. PMID: 32994175.

5. de Ceano-Vivas M, Martin-Espin I, Del Rosal T, Bueno-Barriocanal M, Plata-Gallardo M, RuizDominguez JA, Lopez-Lopez R, Molina-Gutierrez MA, Bote-Gascon P, Gonzalez-Bertolin I, GarciaSanchez P, Martin-Sanchez J, de Miguel-Lavisier B, Sainz T, Baquero-Artigao F, Mendez-Echevarria A, Calvo C. SARS-CoV-2 infection in ambulatory and hospitalised Spanish children. Arch Dis Child. 2020 Aug;105(8):808-809. doi: 10.1136/archdischild-2020-319366. Epub 2020 May 22. PMID: 32444450; 
PMCID: PMC7392480

6. Dosanjh A. COVID 19 and Pediatric Asthma. J Asthma Allergy. 2020 Dec 2;13:647-648. doi: 10.2147/JAA.S291796. PMID: 33299331; PMCID: PMC7720423.

7. Castro-Rodriguez JA, Forno E. Asthma and COVID-19 in children: A systematic review and call for data. Pediatr Pulmonol. 2020 Sep;55(9):2412-2418. doi: 10.1002/ppul.24909. Epub 2020 Jul 6. PMID: 32558360; PMCID: PMC7323291.

8. Floyd GC, Dudley JW, Xiao R, Feudtner C, Taquechel K, Miller K, Henrickson SE, Hill DA, Kenyon CC. Prevalence of asthma in hospitalized and non-hospitalized children with COVID-19. J Allergy Clin Immunol Pract. 2021 May;9(5):2077-2079.e2. doi: 10.1016/j.jaip.2021.02.038. Epub 2021 Mar 3. PMID: 33676051; PMCID: PMC7927636.

9. Sunjaya AP, Allida SM, Di Tanna GL, Jenkins C. Asthma and risk of infection, hospitalization, ICU admission and mortality from COVID-19: Systematic review and meta-analysis. J Asthma. 2021 Apr 1:1-14. doi: 10.1080/02770903.2021.1888116. Epub ahead of print. PMID: 33556287; PMCID: PMC8022341.

10. Kompaniyets L, Agathis NT, Nelson JM, Preston LE, Ko JY, Belay B, Pennington AF, Danielson ML, DeSisto CL, Chevinsky JR, Schieber LZ, Yusuf H, Baggs J, Mac Kenzie WR, Wong KK, Boehmer TK, Gundlapalli AV, Goodman AB. Underlying Medical Conditions Associated With Severe COVID19 Illness Among Children. JAMA Netw Open. 2021 Jun 1;4(6):e2111182. doi: 10.1001/jamanetworkopen.2021.11182. PMID: 34097050; PMCID: PMC8185607.

11. Zhu Z, Hasegawa K, Ma B, Fujiogi M, Camargo CA Jr, Liang L. Association of asthma and its genetic predisposition with the risk of severe COVID-19. J Allergy Clin Immunol. 2020 Aug;146(2):327-329.e4. doi: 10.1016/j.jaci.2020.06.001. Epub 2020 Jun 6. PMID: 32522462; PMCID: PMC7423602.

\section{Hosted file}

Figure legends.docx available at https://authorea.com/users/423360/articles/528808-is-asthmaa-risk-factor-for-covid-19-in-children

\section{Hosted file}

Table 1.docx available at https://authorea.com/users/423360/articles/528808-is-asthma-arisk-factor-for-covid-19-in-children

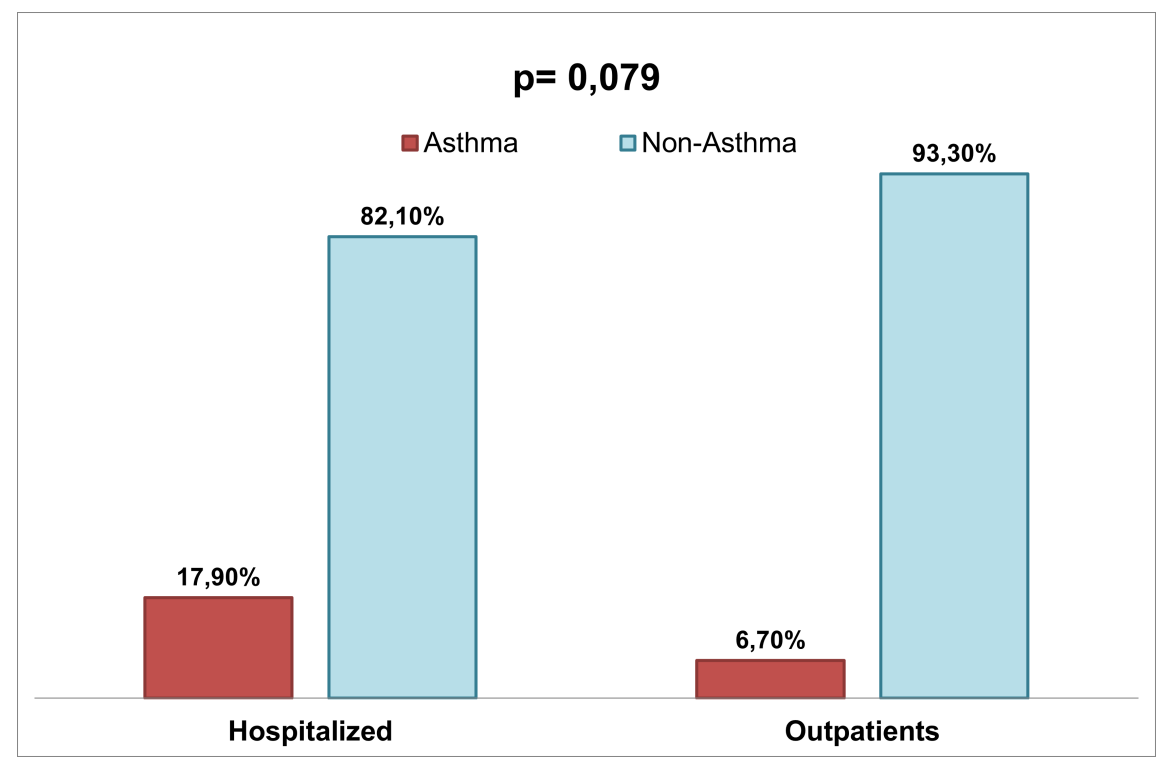




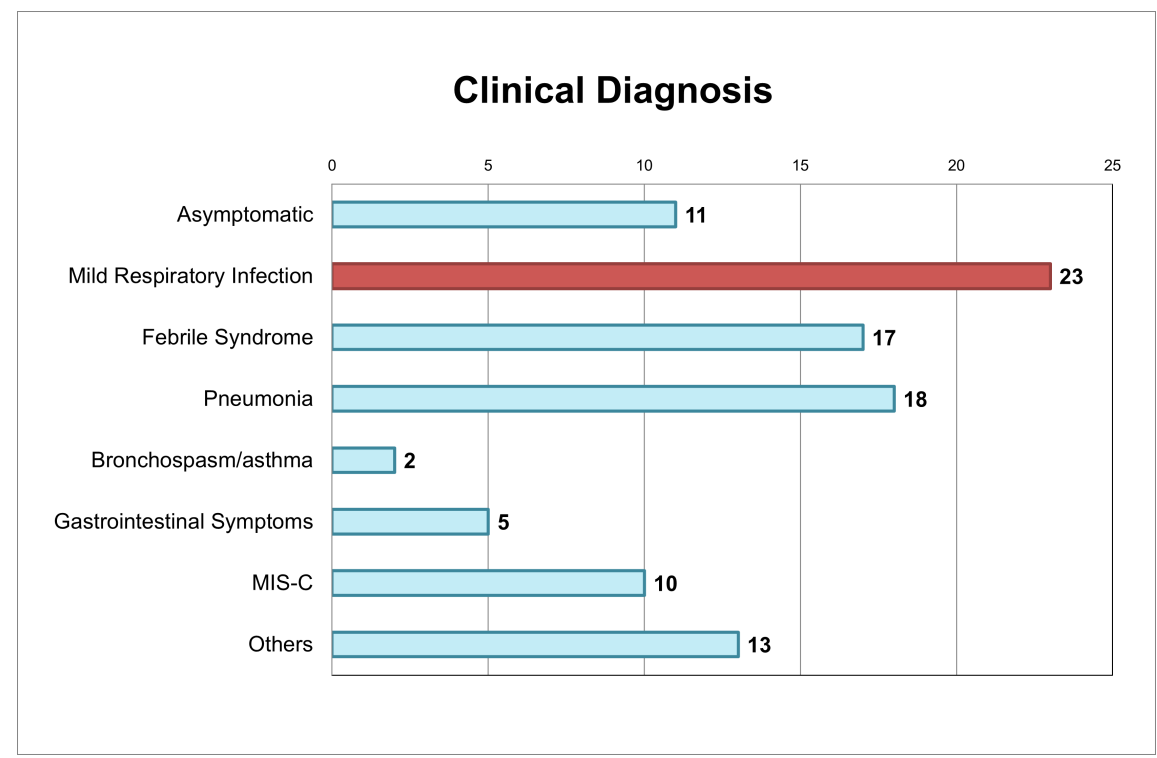

